\section{Synthesis of alumino-silicates}

\section{functionalized titanium as potential adsorbent: An industrial possibility}

Fatima TARIQ - Department of Environmental Sciences, Fatima Jinnah Women University - Fatimatariq86@gmail.com

UZAIRA RAFIQUE - Department of Environmental Sciences, Fatima Jinnah Women University KHURRAM YAQOOB - School of Chemical and Material Engineering

Érkezett: 2017. 10. 19. - Received: 19. 10. 2017. - https://doi.org/10.14382/epitoanyag-jsbcm.2017.16

\begin{abstract}
Nowadays different industrial sectors are highly contributing towards the discharge of heavy metal in various environmental compartments and it is one of the foremost environmental concerns due to their high toxicity and destructive impacts impact on human health. The effluents discharge from paint and leather industries usually contain considerable amount of lead and mercury which ultimately accumulates along the food chain and causes severe damage to the nervous system. Various conventional methods have been reported in past for removing heavy metal ions such as chemical precipitation, electrochemical deposition, solvent extraction, and adsorption. Among these, adsorption is of immense importance because is effective and economical mean for environmental remediation. In past adsorption studies have focused on the development and application of different materials such as silica, titanium, vanadium, alumina, aluminosilicates, chitosan, starch and cyclodextrin. Currently designing of aluminosilicate based materials gain wide acceptance in multidisciplinary research areas due to their distinctive properties such as high surface area, pore volume and low operational cost. In addition to these characteristic features, the application of these materials are limited due to the lack of ion exchange ability which restricts the mobility of metals during adsorption phenomenon The present study was design to functionalize aluminosilicates with titanium chloride in order to enhance its ion exchange properties and ability to reduce harmful state of toxic metals for instance, $\mathrm{Hg}$ (II). The designed materials were subjected to different spectroscopic and quantitative techniques such as fourier transform infrared spectrometry, scanning electron microscopy, X-ray diffractometry. The objective of present research is to prepare aluminosilicate-Ti chloride by adapting simple sol-gel protocol and its functionalization with titanium chloride with simple mixing method. The synthesized material was applied adsorbent for entrapping different toxic pollutants such as mercury and lead. The formation of alumino-silicates-Ti material is confirmed by the presence of distinctive IR peak at $990 \mathrm{~cm}$-1.Scanning electron microscopy of synthesized product reveals the microstructures with small void spaces. The X-ray diffractometry (XRD) pattern reflects the amorphous behaviour of synthesized material due to the modification of aluminosilicate with titanium chloride.

Keywords: aluminosilicates; lead; mercury; adsorbent; sol gel

Kulcsszavak: aluminoszilikátok; ólom; higany; adszorbens; szol gél
\end{abstract}

Fatima TARIQ

Ph.D research scholar from Fatima Jinnah Women University, The Mall, Pakistan is in progress of completing her Ph.D on synthesis of silica hybrids as nanocarrier for targeted drug delivery by functionalizing it with different gatekeepers. She won International Research Support Initiative Program by Higher Education Commission, Pakistan and joined University of Glassow, UK , to work under co-supervision

of Prof. Duncan Gregory on Synthesis and characterization of composite materials research project. Recently she went to University College London, UK to carry out part of her Ph.D research work on computational modelling and application of GULP software on my synthesized materials. She have published several papers which were published in conference proceedings. She filed a patent entitled Synthesis and application of agro- copolymers for treatment of organic

pollutants from waste insulating fluid. Her research interests are in exploring the potential of synthesized composite materials in different fields especially in electrochemistry and adsorption under supervision of Prof. Uzaira Rafique (Dean of Faculty of Sciences, FJWU).

Prof. Uzaira RAFIQUE

Dean of Faculty of Sciences at FJWU Rawalpindi Pakistan. His interests in research group lie in synthesis, structure and physical properties of inorganic, organic, hybrid and composite materials. The basic aim of the group is to discover new materials with potential usefu properties particularly with projected applications in field of environmental remediation and sustainable development.

Dr. Khurram YAQ00BE Received his Bachelor of Metallurgical and Material Engineering degree from University of Engineering and Technology, Lahore, in 2007. Soon after, he was selected by Higher Education Commission of Pakistan for MS Leading to PhD studies from France. He completed his MS in Materials Science from Université Paul Sabatier Toulouse III, France, in 2009, and PhD degree in Materials Science from Université Paris Est, France, in 2012. His PhD research work was dedicated to the experimental determination and thermodynamic modeling of refractory metals phase diagrams. After successful completion of his PhD degree, he has joined Department of Materials Engineering, SCME- NUST as Assistant Professor in 2013

\section{Introduction}

The rapid expansions of human and industrial activities lead towards unusual global and ecological changes. Under these circumstances, the major research target for scientists is to develop economical and environmental functional material by adapting simple methods [3]. Alumino-silicates become the centre of attention after modification with titanium chloride due to its remarkable physiochemical properties such as high surface area to volume ratio and ion exchangeable framework. The replacement of $\mathrm{Si}$ with $\mathrm{Ti}$ in the alumino-silicate framework enables the efficient use of these materials as adsorbent for remediation of heavy metals, volatile hazardous substances and persistent organic pollutants [9]. Recent reports in literature have revealed the possibility of producing aluminosilicate grafted zinc as nanotip by applying different synthesis routes including plasma sprayed, chemical vapour deposition and electrochemical anodization methods [4]. Within anodization method electrolyte and metal variations during synthesis process were reported and their effects were studied on the morphologies of synthesized materials. Additionally, these materials are preferable in the field of adsorption for the remediation of various dyes such as congo red and methylene blue, toxic metals (copper, nickel, lead and mercury) and organic pollutants (pesticides and PCBs) etc from industrial waste water samples [17]. Wang et al., 2012 reported about the modification of silica and alumina with zinc and vanadium to apply as adsorbent for efficient uptake of congo red from 
textile wastewater samples. These materials exhibit significant removal of heavy metals due to its high porosity and large surface area. Similarly after the successive development of silica and alumina based materials, alumino-silicates were also synthesized and modified with zinc extracted from rice husk ashes and its potential application as adsorbent, drug carrier and catalyst due to its high cation exchange capacity. [13] The present study based on the synthesis of alumino-silicates followed by its modification with titanium chloride by using simple and economical sol-gel method. It is proposed that sol-gel method is a possible route to achieve particles with higher homogeneity and uniformity as compared to other conventional means. Based on the economical viability and environmental viable nature of the designed product it serve as nanocage for entrapping various toxic metallic species such as mercury and lead by batch adsorption experiments [6].

\section{Materials and methods}

The materials such as sodium silicate, aluminium nitrate, cetyl trimethylammonium bromide, titanium chloride and $\mathrm{NaOH}$ were the reagents used for synthesis and purchased commercially from Sigma Aldrich. Apparatus include a Flame Atomic Absorption spectrophotometer (AA 220, Varian) for metal analysis.

\subsection{Synthesis of aluminosilicate products}

Fig. 1 shows the synthesis of aluminosilicate by selecting sodium silicate and aluminium nitrate as primary precursors for silica and alumina. For this purpose, alumino-silicate was prepared by dissolving equal proportion (50:50) of both precursors (sodium silicate and aluminium nitrate) in 96 $\mathrm{ml}$ of double deionised water. The homogeneous solution is further processed by the addition of $0.7 \mathrm{ml}$ of $2 \mathrm{M} \mathrm{NaOH}$ with continuous heating and vigorous stirring at $80{ }^{\circ} \mathrm{C}$ for $30 \mathrm{~min}$ followed by uniform mixing of $0.5 \mathrm{~g}$ of surfactants (CTAC). The resultant product was washed with distilled water, filtered and then dried in oven to get white powder which was calcined at $600{ }^{\circ} \mathrm{C}$ for 5 hrs [19]. The prepared product was further functionalized with titanium chloride by simple mixing method. For this purpose, alumino-silicate fine powder was added in titanium chloride solution in (75:25) ratio. The titanium chloride was dissolved in less ratio because highest concentration of it will affect the integrity of the synthesized product [2].The prepared product was coded as AlSi-Ti.

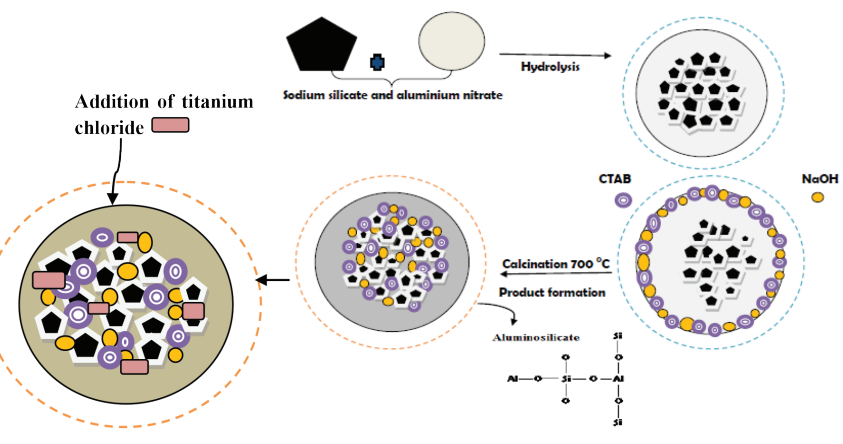

Fig. 1. Synthesis protocol of aluminosilicate material

1. ábra Aluminoszilikát szintézis protokollja

\section{Characterization}

The synthesized material is subjected to following characterization techniques such as FTIR (Fourier Transform Infrared (FTIR-8400 Schimadzu, Japan) spectrophotometer, XRD (STOE) and SEM (JEOL tsm-6490, Japan).

\subsection{FTIR}

The appearance of small IR peak at $997 \mathrm{~cm}^{-1}$ was assigned due to the formation of $\mathrm{Si}-\mathrm{O}-\mathrm{Al}$ bond after condensation of $\mathrm{Si}-\mathrm{OH}$ and $\mathrm{Al}-\mathrm{OH}$ groups [15] but modification of aluminosilicate with titanium chloride was confirmed by the shift in IR peak from $997-990 \mathrm{~cm}^{-1}$ and it corresponds to the stretching vibration of $\mathrm{Si}-\mathrm{O}-\mathrm{Al}[6]$ perturbed by the presence of vibration band of the -Al-O- Ti-O-Si [11] fragment The reduction in the intensity of IR peaks of alumino-silicate-Ti sample confirms the modification (see Fig. 2).

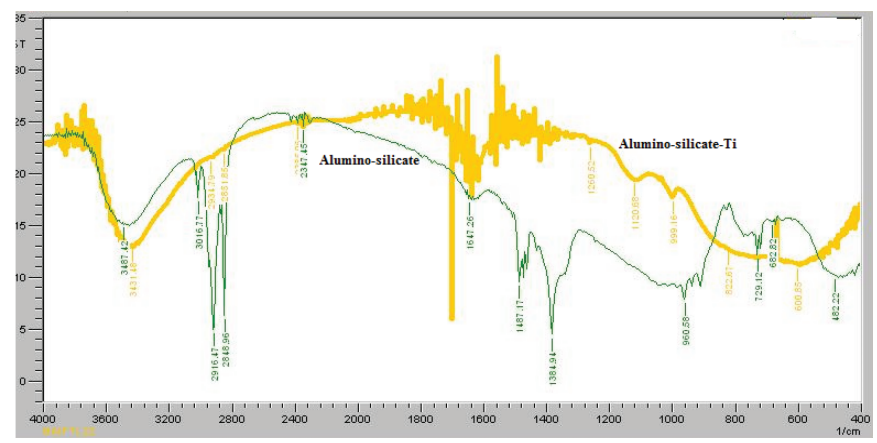

Fig 2. FTIR spectra of alumino-silicate-Ti based material

2. ábra Titán-aluminoszilikát FTIR spektruma

\subsection{SEM}

SEM micrograph of AlSi-Ti seen in Fig. 3 showed aggregation of particles [12] with large number of small void spaces. This might be due to the effect of high calcinations temperature or attributed to the addition of cationic surfactant (CTAC) during synthesis [3].

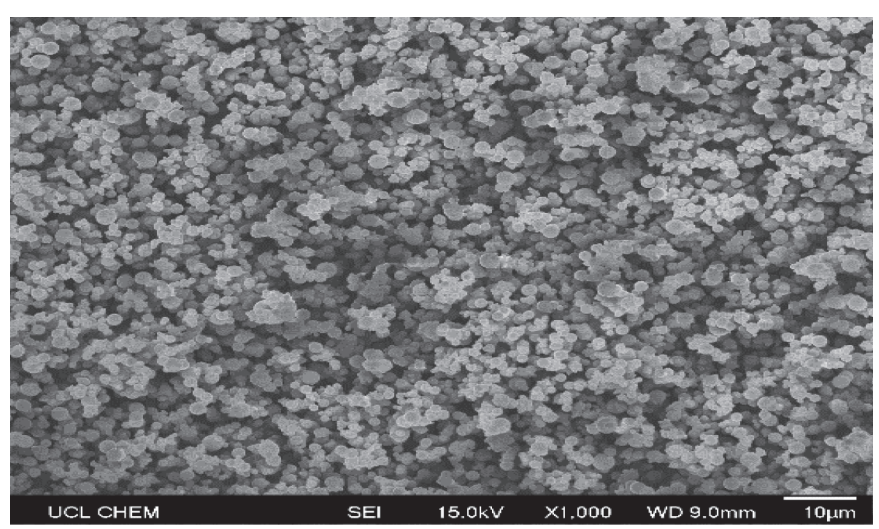

Fig. 3. SEM of alumino-silicate-Ti based material

3. ábra Titán-aluminoszilikát elektronmikroszkópos felvétele

\section{$3.3 \mathrm{XRD}$}

XRD pattern of synthesized specimen scanned at 10-71 of $2 \theta$ by steps of 0.015 with $\mathrm{Cu} \mathrm{K}$ a radiation $(\lambda=1.54059)$ clearly depicts the amorphous nature of synthesized material. It is 
attributed to the instability of AlSi-Ti material under acidic conditions which may lead towards the dealumination and collapse of atomic structures. This study is also supported by the Lin et al., 2015 which reveals the reduction in the peak intensities of the crystalline kaolinite after modification with Ti [18], see Fig. 4.

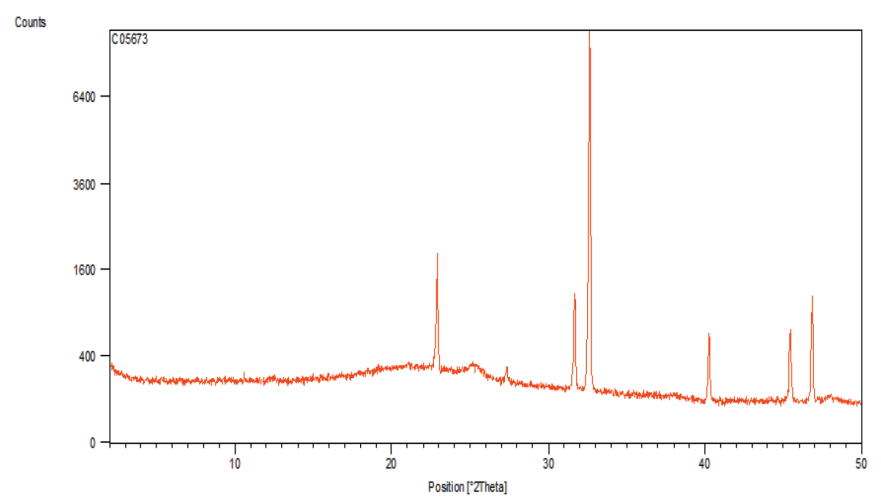

Fig. 4. XRD of alumino-silicate-Ti based material

4. ábra Titán-aluminoszilikát röntgendiffraktogramja

\subsection{Batch adsorption experiment}

A batch method was employed to study the adsorption of mercury and lead from aqueous solutions onto the aluminosilicate matrix. For this purposes, adsorbent $10 \mathrm{mg}$ was suspended in 30, 50 and $70 \mathrm{mg} / \mathrm{L}$ of aqueous solution. Known concentration of adsorbate $(0.03 \mathrm{mg} / \mathrm{L})$ is pipetted out in the flask containing $10 \mathrm{mg}$ of adsorbent (alumino-silicate), after the contact of every 5 minutes and analysed under flame atomic absorption spectrometer (FAAS) [7]. Percent removal was calculated by using following equation:

$$
\mathrm{R} \%=\mathrm{Ci}-\mathrm{Co} / \mathrm{Ci}
$$

It is proposed on the basis of experimental results that alumino-silicate modified titanium composites reveal (69\%) uptake of mercury after 15 min minutes as shown in Fig. 5.a. It is attributed to the availability of large surface area and number of free binding sites. The slight decrease in adsorption of mercury ions is associated with the aggregation of available active sites as a result electrostatic attraction diminishes between mercury ions and adsorbent surface. This ultimately decreases the diffusion path length of the adsorbent [5]. (a)

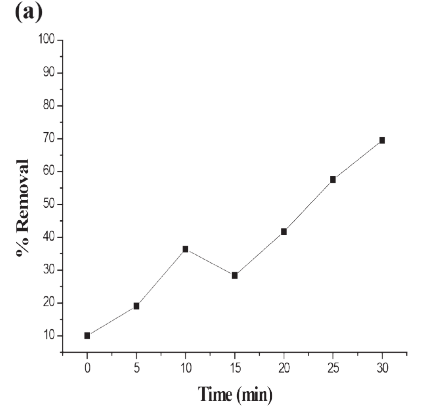

(b)

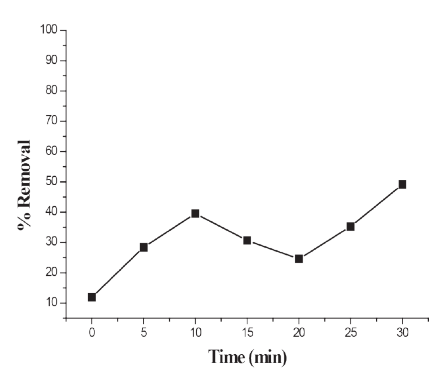

Fig. 5. Removal percentage (a) mercury, (b) lead 5. ábra Eltávolítási hányadok (a) higany, (b) ólom

In addition, gradual uptake of $\mathrm{Pb}^{2+}$ ion (49\%) was recorded at initial 10 minutes is due to the quick saturation of all empty active sites [1] and rapid diffusion of lead ions may accelerate the affinity of adsorbent to remove lead at initial time but quick decline after 10 minutes till 20 minutes is attributed to the surface coverage of alumino-silicate-Ti adsorbent results in the formation of metal complexes [10] (see Fig. 5.b)

Comparative adsorption studies of alumino-silicates-Ti with both metals (lead and mercury) suggest Accordingly it can be found that regular incline is observed for the removal of mercury as compared to lead. This adsorption trend is allied with the generation of unsaturated negative charge due to replacement of $\mathrm{Si}^{4+}$ ions by $\mathrm{Al}^{3+}$ in the alumino-silicate skeleton. Consequently lowest percentage removal of lead is observed at $20 \mathrm{~min}$ is due to the long-distance diffusion of lead ions into the internal pores of alumino-silicates framework [16].

\section{Conclusions}

It is concluded that physicochemical properties of aluminosilicates after modification serve as superior material for various industrial applications due to its bidimensional oxide structure in which the metals are bound to the $\mathrm{Al}_{2} \mathrm{O}_{3}$ matrix by $\mathrm{SiO}-\mathrm{Ti}$ bond. Specific advantages to be gained by using alumino-silicates-Ti nanoparticles include facile adsorption, desorption, separations and catalysis applications. Efficient removal of mercury as compared to lead is observed due to the presence of electrostatic interactions between negative surfaces of alumino-silicates- $\mathrm{Ti}$ with the positive charge of mercury ion whereas removal of lead was significantly low due to the neutral charge of lead ion. It is concluded that modification of alumino-silicates with titanium chloride was favourable due to its potent economical and environmental benefits.

\section{References}

[1] K. M. Alam - P. A . Singh - C. S. Bodepudi - S. Pramanik (2011): Fabrication of hexagonally ordered nanopores in anodic alumina: An alternative pretreatment, Surface Science Vol. 605, No. 3-4, February 2011, pp. 441-449. https://doi.org/10.1016/j.susc.2010.11.015

[2] M. S. Auerbach - W. Fan - A. P. Monson (2015): Modelling the assembly of nanoporous silica materials, International Reviews in Physical Chemistry, Vol. 34, No. 1, pp. 35-70. https://doi.org/10.1080/0144235X.2014.988038

[3] G. Bellussi - R. Millini - E. Montanari - A. Carati - C. Rizzo - O. W. Parker - S. Zanardi (2012): A highly crystalline microporous hybrid organic-inorganic aluminosilicate resembling the AFI-type zeolite, Chemical Communications, Vol. 48, No. 59, pp. 7356-7358. https://doi.org/10.1039/C5SC01912E

[4] I. S. Chaturvedi (2013): Mercury Removal Using Al-Al Electrodes by Electrocoagulation, International Journal of Modern Engineering Research, Vol. 3, No. 1, pp. 109-115.

[5] Q. Chen - C. Boothroyd - M. A Soutar - T. X. Zeng (2010): Sol-gel nanocoating on commercial $\mathrm{TiO} 2$ nanopowder using ultrasound, Journal of sol-gel science and technology, Vol. 53, No. 1, pp. 115-120. https://doi.org/10.1007/s10971-009-2066-3

[6] S. Deng - M. Kurttepeli - J. D. Cott - D. S. Bals - C. Detavernier (2015): Porous nanostructured metal oxides synthesized through atomic layer deposition on a carbonaceous template followed by calcination, Journal of Materials Chemistry A, Vol. 3, No. 6, pp. 2642-2649. https://doi.org/10.1039/C4TA05165C

[7] S. Dursun - A. Pala (2007): Lead pollution removal from water using a natural zeolite, J. Int. Environmental Application \& Science, Vol. 2, No. 2, pp. 11-19.

[8] J. Fang - I. Levchenko - K. Ostrikov (2014): Free-standing alumina nanobottles and nanotubes pre-integrated into nanoporous alumina membranes, Science and Technology of Advanced Materials, Vol. 15, No. 4. https://doi.org/10.1088/1468-6996/15/4/045004 
[9] X. Lin - N. Zhao - P. Yan - P. H. Hu - F. J. Xu (2015): The shape and size effects of polycation functionalized silica nanoparticles on gene transfection, Acta Biomaterialia, Vol. 11, pp. 392. https://doi.org/10.1016/j.actbio.2014.09.004

[10] D. Macina - Z. Piwowarska - K. Tarach - K. Góra- Marek - J. Ryczkowski - L. Chmielarz (2016): Mesoporous silica materials modified with alumina polycations as catalysts for the synthesis of dimethyl ether from methanol, Materials Research Bulletin, Vol. 74, pp. 425-435. https://doi.org/10.1016/j.materresbull.2015.11.018

[11] Liu, M. - Hou, L. - Xi, B. - Zhao, Y. - Xia, X. (2013): Synthesis, characterization, and mercury adsorption properties of hybrid mesoporous aluminosilicate sieve prepared with fly ash, Applied Surface Science, Vol. 273, pp. 706-716. https://doi.org/10.1016/j.apsusc.2013.02.116

[12] P. Misaelides (2011): Application of natural zeolites in environmental remediation: A short review, Microporous and Mesoporous Materials, Vol. 144, No. 1, pp. 15-18. https://doi.org/10.1016/j.micromeso.2011.03.024

[13] L. Rita - T. Amit - G. Chandrashekhar (2011): Current trends in $\beta$-cyclodextrin based drug delivery systems, International Journal of Research in Ayurveda and Pharmacy, Vol. 2, pp. 1520-1526.

[14] S. Simon - M. Tămăşan - T. Radu - V. Simon (211): Doping and calcination effect on nanostructured aluminosilicates processed by sol-gel route, The European Physical Journal-Applied Physics, Vol. 55, No. 3, pp. 10-15. https://doi.org/10.1051/epjap/2011100524

[15] J. R. Sohn - C. K. Lee (2007): Effect of $\mathrm{V}_{2} \mathrm{O}_{5}$ Modification in $\mathrm{V}_{2} \mathrm{O}_{5} / \mathrm{TiO}_{2}$ $\mathrm{ZrO}_{2}$ Catalysts on Their Surface Properties and Catalytic Activities for Acid Catalysis, Bulletin of the Korean Chemical Society, Vol. 28, No. 12, pp. 2459-2465. https://doi.org/10.5012/bkcs.2007.28.12.2459

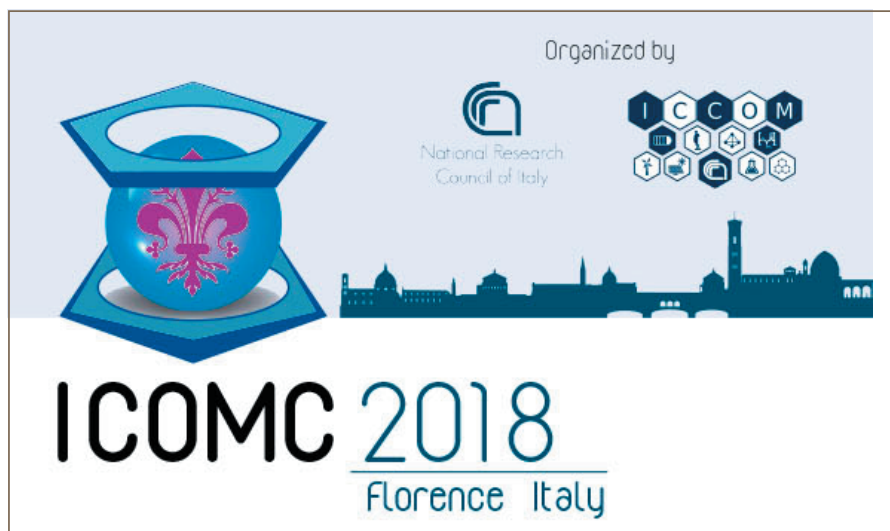

\section{8th International Conference on Organometallic Chemistry}

\author{
FLORENCE, ITALY \\ Congress \& Exhibition Centre
}

$15-20$ JUL $Y 2018$

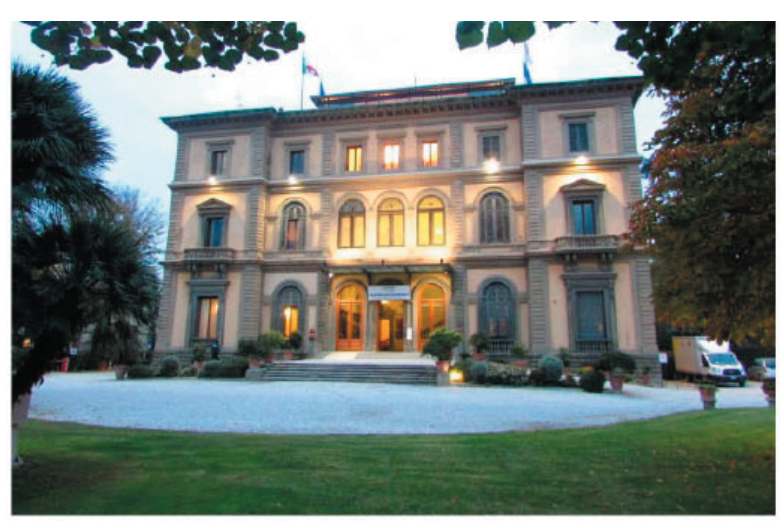

www.icomc2018.com
[16] Y. Wang - C. Bryan - H. Xu - P. Pohl - Y. Yang - C. J. Brinker (2002): Interface Chemistry of Nanostructured Materials: Ion Adsorption on Mesoporous Alumina, Journal of colloid and interface science, Vol. 254, No. 1, pp. 23-30. https://doi.org/10.1006/jcis.2002.8571

[17] A. A. Warra (2011): Transition metal complexes and their application in drugs and cosmetics - A Review, Journal of Chemical and Pharmaceutical Research, Vol. 3, No. 4, pp. 951-958.

[18] Y. Yan - Y. Zhang - G. Meng - L. Zhang (2006): Synthesis of ZnO nanocrystals with novel hierarchical structures via atmosphere pressure physical vapor deposition method, Journal of crystal growth, Vol. 294, No. 2, pp. 184-190. https://doi.org/10.1016/j.jcrysgro.2006.06.049

[19] Y. Zhang - Z. He - H. Wang - L. Qi - G. Liu - X. Xang (2015): Applications of hollow nanomaterials in environmental remediation and monitoring: A review, Frontiers of Environmental Science \& Engineering, Vol. 9, No. 5, pp. 770-783. https://doi.org/10.1007/s11783-015-0811-0

$\underline{\text { Ref.: }}$

Tariq, Fatima - Rafique, Uzaira - Yaqoob, Khurram: Synthesis of alumino-silicates functionalized titanium as potential adsorbent: An industrial possibility

Építőanyag - Journal of Silicate Based and Composite Materials, Vol. 69, No. 3 (2017), 94-97. p.

https://doi.org/10.14382/epitoanyag-jsbcm.2017.16

On behalf of the Organising Committee, it is our great pleasure to invite you to attend the 28th International Conference on Organometallic Chemistry (ICOMC-2018) which will be held from 15th to 20th of July 2018 at the Congress and Exhibition Centre in the heart of the city of Florence, Italy, organised by the Institute of chemistry of Organometallic Compounds (ICCOM) of the Italian National Research Council (CNR), in association with the official PCO of the event, Adria Congrex Srl.

The Conference comes back to Italy after 30 years (Turin 1988) as a part of a series of biannual events with a long tradition. ICOMC 2018 will provide a unique opportunity to present and disseminate all the main aspects of modern organometallic chemistry in a lively, multidisciplinary and modern environment. Companies ar e welcome to support the conference by various kinds of Sponsorhip and will find exhibition space and other opportunities to advertise their products and activities.

The scientific program will be organised in parallel Lecture Sessions, focused on different aspects of traditional and emerging areas of organometallic chemistry and related applications. Student attendance will be encouraged by reduced fees and giving the possibility to showcase their results during two Poster Sessions and Flash Presentations. Top poster contributions will be shortlisted for poster Prizes. 